\title{
Does Gamifying Homework Influence Performance and Perceived Gameful Experience?
}

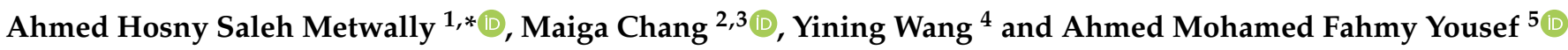 \\ 1 School of Information Science and Technology, Northeast Normal University, Changchun 130117, China \\ 2 School of Computing and Information Systems, Athabasca University, Edmonton, AB T5J 3S8, Canada; \\ maiga.chang@gmail.com \\ 3 Department of M-Commerce and Multimedia Applications, Asia University, Taichung 41354, Taiwan \\ 4 School of Media Science, Northeast Normal University, Changchun 130117, China; wangyn814@nenu.edu.cn \\ 5 Faculty of Specific Education, Fayoum University, Fayoum 63514, Egypt; ahmed.fahmy@fayoum.edu.eg \\ * Correspondence: ahmed_hosny@nenu.edu.cn
}

Citation: Metwally, A.H.S.; Chang, M.; Wang, Y.; Yousef, A.M.F. Does Gamifying Homework Influence Performance and Perceived Gameful Experience? Sustainability 2021, 13, 4829. https://doi.org/10.3390/ su13094829

Academic Editors: Daniel Burgos and Víctor Abella García

Received: 3 February 2021

Accepted: 24 March 2021

Published: 25 April 2021

Publisher's Note: MDPI stays neutral with regard to jurisdictional claims in published maps and institutional affiliations.

Copyright: (c) 2021 by the authors. Licensee MDPI, Basel, Switzerland. This article is an open access article distributed under the terms and conditions of the Creative Commons Attribution (CC BY) license (https:// creativecommons.org/licenses/by/ $4.0 /)$.

\begin{abstract}
There is a growing body of literature that recognizes the importance of applying gamification in educational settings. This research developed an application to gamify students' homework to address the concern of the students' inability to complete their homework. This research aims to investigate students' performance in doing their homework, and reflections and perceptions of the gameful experience in gamified homework exercises. Based on the data gathered from experimental and control groups $(\mathrm{N}=84)$ via learning analytics, survey, and interview, the results show a high level of satisfaction according to students' feedback. The most noticeable finding to extract from the analysis is that students can take on a persona, earn points, and experience a deeper sense of achievement through doing the gamified homework. Moreover, the students, on the whole, are likely to be intrinsically motivated whenever the homework is attributed to factors under their own control, when they consider that they have the expertise to be successful learners to achieve their desired objectives, and when they are interested in dealing with the homework for learning, not just achieving high grades.
\end{abstract}

Keywords: gamification; gamifying homework; feedback; satisfaction; user experience; completion rate

\section{Introduction}

Using gamification in the classroom can enhance the learning process and motivate students to learn. Gamification is meant to make learning more engaging by using game features to support learning processes [1]. An implicit feature of gamification is the gameful experience which refers to "the positive emotional and involving qualities of using a gamified application" [2]. Chee and Wong referred to the fundamental aspects of game design and the game natures like behavioral complexities, and the hedonic which were abandoned in the applications and directed our considerations to novelty, curiosity, exploration, challenge, and aesthetic value to enforce extrinsic motivators integration [3].

Gamification practices have several challenges with applying game elements in different contexts, which restrain identifying its effects on the learning outcomes and the perceived gameful experience. Overall, there is variation in the results of gamification studies when applying different systems in different contexts and objectives which leads to inconsistency [4]. To fill this gap, gamifying an activity in a certain context in education could help to recognize its effect [5]. Thus, gamification studies in supporting learning English as a second language reported positive effects on both the learning experience and outcomes [6], including language acquisition [7]. Zarzycka-Piskorz [8] referred to applying game elements and extrinsic motivators in learning English grammar after using "Kahoot!" motivated students regarding the competitiveness aspect. 
Homework is one of the controversial issues that carries two sides. The educational advantages of homework can help students outside the classroom domain to support their learning; however, they are required to accomplish the assignments of each subject whereas the allowed time to complete it is not enough. Furthermore, homework can affect students' physical and mental health in addition to causing academic stress and lack of balance in their lives [9]. The negative effect reflects on academic achievement [10].

To overcome these issues, gamification literature suggests focusing on situational contexts, developing new forms of innovative research, and prosperous design of applications $[5,11]$. Therefore, a gamification approach to homework assignments can motivate students in learning and homework accomplishment [12-15]. The results showed a positive effect on motivation and completing the assignments. Most of the studies focused on investigating motivation and academic achievement for higher education level and university students. The current evidence in this regard recommended paying particular attention to students' responses in the gamified homework and focusing on learners' experiences and perceptions of gamification in the future $[13,16]$, especially for primary education homework $[17,18]$. Furthermore, there is no agreement about the effect of homework on students' performance [18].

There are unexplored questions concerning students' reflections and perceived experience when gamifying homework for K-12 students. Therefore, employing further investigation of gameful experiences and homework performance is crucial to recognize the relationship between gamifying K-12 students' homework and the ability to complete learning tasks. This research aims at investigating students' perceptions and reflections of the gameful experience in the gamified homework and identifying the effects of using the gamification elements on completing the homework assignments.

To investigate the effects of the gamified homework on students' perceptions of the gameful experience and evaluate their performance in completing homework exercises, a quasi-experimental study on primary school students was conducted. Consequently, this research addresses the following research questions:

RQ (1): What are the differences between the experimental and control groups in the homework completion regarding the final score?

RQ (2): What are the differences between the experimental and control groups in the homework completion rates?

RQ (3): What is the perceived feedback about completing homework assignments between the experimental and control groups?

RQ (4): How do students perceive the gamified homework experience?

The findings can contribute significantly to gamification literature by supporting teachers, instructional designers, and researchers with the main inclusions that support their understanding of implementing gamification applications in school homework. It provides the systematic instructional design process for educators and designers as guidance to gamify learning assignments. Moreover, it explores students' perceptions of the gameful experience regarding the homework context and other factors such as time spent and homework completion rate, which enhance our understanding with evidence derived from quantitative and qualitative methods.

This research is structured as follows: Section 2 presents work related to this research. Section 3 includes the research methods. Section 4 demonstrates the process of gamifying homework followed by the results in Section 5. We discussed the results in Section 6. Finally, Section 7 summarizes the research conclusion with the limitations and recommendations for future work.

\section{Related work}

Since gamification was reported by Nick Pelling in 2002, it attracted a lot of interest in technology-enhanced Learning (TEL) [19]. "The use of game design elements in nongame contexts" is a popular definition of gamification [20]. Gamification is a methodology that includes technological domains, and a multidisciplinary research field that connects 
with different fields; one of the most closely related research field is education [5,21]. Extensive research has shown that gamification of learning is "the use of game logics (components, mechanics, and dynamics) and game aesthetics designed to promote and enhance learning through motivation (seen as the combination of the elements of attention, relevance, confidence, and satisfaction)" [4].

Most of the reported outcomes of using gamification in education were psychological outcomes represented in engagement, motivation, and involvement [22]. Recently, the gameful experience found a special interest in gamification literature. It can be defined as a "psychological state resulting from the interaction of three psychological characteristics: perceiving presented goals to be non-trivial and achievable, being motivated to pursue those goals under arbitrary externally-imposed constraints, and believing that one's actions within these constraints to be volitional [23]." Accordingly, the prevalent psychological outcomes in gamification research involved "the perceptions of use, use experience, perceived enjoyment, and fun [24]."

A substantial amount of research focused on achievement and progression as the most used affordances which involve point, challenge, badge, and leaderboard [24]. There is a remarkable emergence in the number of quantitative and qualitative gamification studies from 2013 to 2016 [25]. Although gamification research has reached an advanced level of maturity, it is considered to be in an early stage in the long term [11]. Thus, many research endeavors have sought to study the impact of gamification in education.

Focusing on the educational context, homework is an essential part of pedagogical practices. It is defined as "tasks assigned to students by school teachers that are meant to be carried out during non-school hours" [26]. It plays a critical role in enhancing learning, achievement, performance, and supporting communication $[17,27]$. Fan et al. [28] figured out the effective impact of homework on math and science achievement for primary school students. Moreover, the positive relationship between homework and academic achievement is better in post-primary grades than in K-6 [17]. Magalhães et al. [18] refer to the homework performance indicators that could be "retention of knowledge, exam and final grades, homework assignments completed, overall performance". Results showed that homework in different formats had positive results for increasing and keeping students' performance $[29,30]$. Bembenutty and White [31] indicated the importance of homework logs and intrinsic motivation for the academic performance that reflects on students' satisfaction.

Given the importance of implementing gamification in the homework context, there are promising endeavors that elucidated the positive effects of using gamification for achieving homework assignments. Goehle and Wagaman [13] denoted that students appreciated and enjoyed using gamification elements in doing their online homework. Gamification increased primary school students' disposition to experience flow when applied in a social learning environment (SLE) with a set of learning activities as homework tasks [32]. More recent investigation has supported the positive impact of gamifying homework on primary school students' enjoyment, intrinsic motivation, and satisfaction [33]. Kulhanek et al. [14] reported that university engineering students felt empowered, interested, motivated towards completing the assignments where a gamification platform was applied.

Regarding gamification elements, levels and achievements have been employed in mathematics homework. Students felt supported, enjoyed, and tracked their levels and achievements [34]. Other studies indicated the importance of integrating badges with homework systems to help university students for homework submission before the deadline which reflected on their efforts to obtain the badge that rewards the highest score, and impacted their behavior $[35,36]$. Furthermore, implementing points, levels, leaderboards, badges, progress bars, achievements, and awards in a quest-based portal showed the neutral effects of the gamified environment on the academic motivation towards homework; however, there is a positive impact of the platform regarding the motivation and feedback support for homework [12]. Overall, most of the studies supported the positive impact of implemented game elements in homework assignments. 


\section{Methods}

The design science research (DSR) approach intends to create and evaluate artifacts to solve identified problems and evaluate artifacts to solve identified problems and needs [37]. This investigation takes the form of a user evaluation study employing an iterative design process, and adopts a quasi-experimental design [38] for assessing the effect of the applied game elements when students are doing the homework assignments. Furthermore, it applied a qualitative method [39] to explicate the complicated process of gamification [40]. This would bring the strengths to understand students' perception and evaluate gamification's role in learning assignments.

\subsection{Settings and Participants}

Given the study objectives, the research employed a quasi-experimental design in which students were randomly divided into two groups, i.e., an experimental group and a control group. The experimental group of students used gamification elements when accomplishing the homework on the platform, while the control group of students did the regular homework assignments without using the gamification elements on the same platform. The same homework assignments were associated with both the groups aside from the instructions for using the gamified homework platform. To promote participation, gamification features such as freebies, points, badges, and other elements were used. It was the application of game design mechanisms to non-game contexts with the goal of increasing involvement, interaction, and student loyalty.

Participants in this intervention were students on a voluntary basis. They were selected from an Egyptian public school to form the two groups. Respecting the ethics of scientific research in dealing with children's behavior, study approval was acquired from parents or the child's legal representative. Eighty-four sixth-grade Egyptian primary school students studying English were randomly assigned to the groups (40 students in the experiment group and 44 students in the control group). For the interview, fourteen (14) students participated in the interview session from the experiment group to express their feelings, their experience, and their perceptions of the gamified homework. All participants' information was kept anonymous and confidential.

To identify students' feedback and perceptions during the experiment, there was an intercept optional survey (pop-up survey)., which was used as a satisfaction survey [41]. It provided a direct method in accordance with their experience during homework completion as illustrated in Table 1. This method considers a quick evaluation method to understand the initial responses of students and give indicators of the results.

Table 1. Feedback survey questions.

\begin{tabular}{|c|c|c|c|c|}
\hline Question & \multicolumn{4}{|c|}{ Responses } \\
\hline $\begin{array}{l}\text { learning with } \\
\text { the platform? }\end{array}$ & Not really & Maybe & Yes & Very much \\
\hline $\begin{array}{l}\text { How does doing } \\
\text { the homework } \\
\text { make you feel? }\end{array}$ & Active & Focused & Bored & Motivated \\
\hline $\begin{array}{l}\text { What do you } \\
\text { like most in this } \\
\text { homework? }\end{array}$ & Collaboration & Competition & $\begin{array}{l}\text { Freedom to } \\
\text { create }\end{array}$ & Challenge \\
\hline $\begin{array}{l}\text { Did you put a } \\
\text { great deal of } \\
\text { effort into } \\
\text { advancing your } \\
\text { learning through } \\
\text { this platform? }\end{array}$ & $\begin{array}{l}\text { I have always } \\
\text { had a very hard } \\
\text { time trying to } \\
\text { finish this } \\
\text { homework }\end{array}$ & $\begin{array}{l}\text { I spent at least } \\
20-30 \text { min per } \\
\text { night on } \\
\text { homework }\end{array}$ & $\begin{array}{c}\text { I have spent too } \\
\text { much time in } \\
\text { doing my } \\
\text { homework }\end{array}$ & $\begin{array}{l}\text { I read through } \\
\text { each lesson } \\
\text { before starting } \\
\text { the homework }\end{array}$ \\
\hline
\end{tabular}


The archived data of student's activities on the platform's back-end provided a detailed analysis of and insights into the homework exercises' completion rate to reflect homework performance. Furthermore, a semi-structured interview was also carried out after the experiment to identify students' perceived gameful experience. Interview questions were prepared based on the literature on gamification and the research objectives. It was examined by two experts and included the following questions: (1) What was it about the game you played that was most helpful to your learning? (2) How many points do you expect to earn in this game? (3) What parts of the game were obstacles to your learning? and (4) Do you have any specific recommendations for improving this educational game? The researchers used questions for screening and follow-up (e.g., "How is that?", "What does it mean?" and "Tell me some more"). Each interview lasted around $20 \mathrm{~min}$.

\subsection{Procedure}

Gamifying homework requires following systematic procedures to achieve gamification goals in educational settings. After reviewing the literature, we found that the majority of models follow a similar process. The seven-phase process was adopted from [42] as shown in Table 2.

Table 2. The main processes and activities of gamifying homework.

\begin{tabular}{|c|c|}
\hline Process & Activities \\
\hline Preparation & Defining the objectives; identifying requirements \\
\hline Analysis & User analysis; context analysis \\
\hline Ideation & Thinking about new ideas; design techniques and tools \\
\hline Design & Prototype; use cases; homework exercises; design a scenario \\
\hline Implementation & Implementing design; manage implementation; testing \\
\hline Evaluation & The quantitative results; the qualitative results \\
\hline Monitoring & Improvements list \\
\hline
\end{tabular}

The process starts with the initial phase of preparation and analysis that includes identifying the objectives of the gamified application and applying the main analysis of users and context. The following phases are ideation, design, and implementation respectively, in which the main activities in these phases are proposing the design ideas, thinking about the prototypes, and developing the design by using the authoring tools. The evaluation phase involves assessing the students' perceived experience. In this phase, we reported the results of the total number of points on the system which reflects student scores in addition to analyzing the activities during the time of the experiment. Moreover, the embedded quick survey meant reflecting the feedback towards the gamified homework. The qualitative results of the interview were applied for understanding students' satisfaction and reflection of the study experience. The last phase, monitoring, aims to revise the application overall and enhance the design process and practices.

The next section will focus on presenting the first five phases of gamifying homework, the evaluation phase will be addressed by the Results section, and the monitoring phase will be discussed and summarized in the Discussion section.

\section{Gamifying Homework Process}

\subsection{Preparation and Analysis}

In the preparation phase, we came up with the initial queries such as deciding the solution, defining the objectives of gamifying homework, and identifying the experiment requirements (including the deadline of executing, constraints, and the required resources).

The analysis phase concerned users and context analysis. During this phase, we selected sixth-grade students who study English in the first semester of the academic year $2019 / 2020$. The results of the first iteration in the authors' previous work covered the need 
for a motivational solution for helping students in their homework achievements [33]. The analysis of students' needs revealed that they are willing to use gamification in school assignments. Regarding context analysis, employing gamification design elements was implemented by using an online gamified platform. We chose two units of the English course: Unit 3 "Daily Activities" and Unit 4 "Visiting a Film Studio".

\subsection{Ideation}

It aims to think of new and creative design ideas. We reviewed the literature and the published gamification projects, gamification apps, and games from both theoretical and practical perspectives. We also applied a set of techniques like board and video games, and best practice/gamification patterns [42] to underpin our thoughts of the design. Thinking about the design idea led to "Find the Treasure" which is the name of the gamified homework. This design distributed the homework exercises of Units 3 and 4 in different places on the map. The mission for each student in the experimental group was to find the treasure by completing the homework exercises of Units 3 and 4, collecting points and badges, and advancing the level. Therefore, game elements include points, achievement badges, scoreboard, time constraints, levels, unlock items, challenges, feedback, and achieving the mission to reach the Win state.

\subsection{Design of Prototype}

We created a visual mockup of the application using hand drawings. The ideas of design could be appraised and discussed with a group of users genuinely as shown in Figure 1.

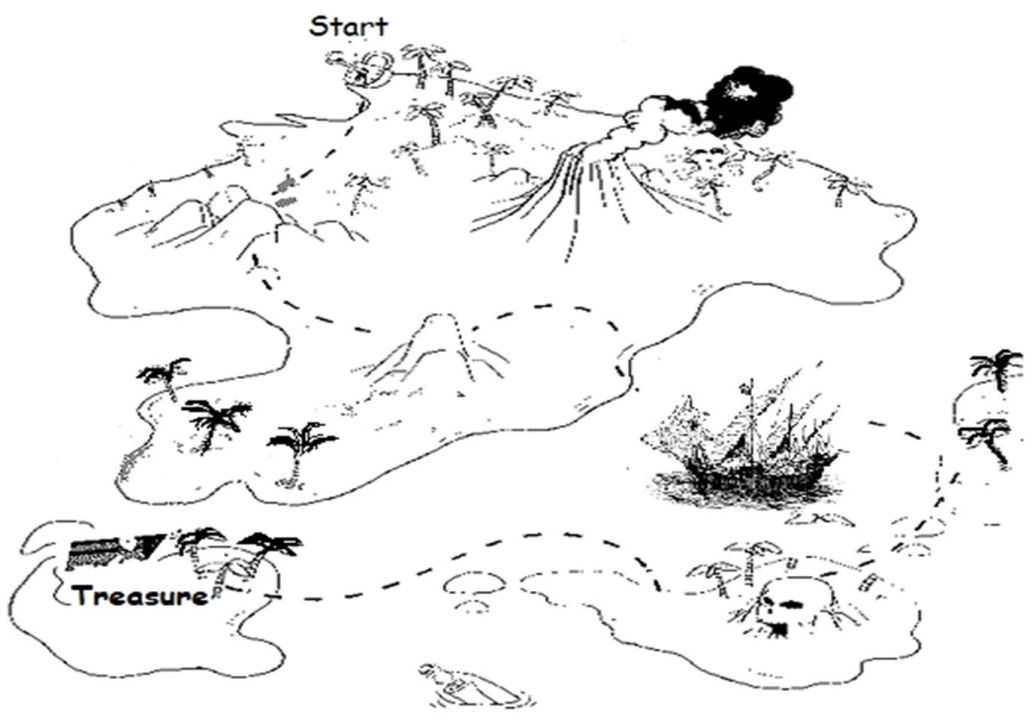

Figure 1. The paper prototype of the design.

The paper prototype aimed to determine the use cases of the gamification app. The use cases of the students are meant to describe how students will achieve their homework on the gamification system [43]. Therefore, use cases are useful for clarifying the responses of the system when the students request some functions, which are beneficial to develop the design for the next phase.

Coming up with the unit content analysis and providing the supporting materials and resources for preparing several kinds of questions is essential in this phase. The question types involved multiple-choice, filling the gap with a short answer, matching, and arranging in order [44] to cover the English language skills that included listening, reading, and writing skills. Therefore, the established homework was created and shaped into the main exercises to reflect the units' structure. Furthermore, identifying the gamification elements is crucial in the design phase. We used a previously proposed and evaluated taxonomy to analyze the game elements used in gamified learning environments. Then, 
we considered implementing the game elements derived from dynamics, mechanics, and components [45], as listed in Table 3, to support completion behavior and provide the opportunity to practice homework exercises [46].

Table 3. The list of used game elements.

\begin{tabular}{|c|c|}
\hline Elements & Description \\
\hline Points & The obtained score to reward students after answering the question. \\
\hline Badge & $\begin{array}{l}\text { Visual feedback to symbolize rewards if students obtained a specific number of points or } \\
\text { answered the exercise under a set of conditions. }\end{array}$ \\
\hline Levels & $\begin{array}{l}\text { Gradual achievement stages to reach the milestone in which answering the exercises advances } \\
\text { students' status and could represent their achievement. }\end{array}$ \\
\hline Progression & The visual representation to identify students' position towards completing the homework. \\
\hline Challenges & $\begin{array}{c}\text { Advanced level of questions that necessitate focused attention and high-level skill to match the } \\
\text { right answer. }\end{array}$ \\
\hline Chance & Attempts to answer the questions if the answer was wrong, up to three attempts. \\
\hline Time Constraints & $\begin{array}{l}\text { The limitation of the available time for completing the exercise which stimulates the quick } \\
\text { responses of students. }\end{array}$ \\
\hline Locked Items & $\begin{array}{c}\text { Items requiring students' response or action to be opened such as the exercises which entail } \\
\text { writing the passcode. }\end{array}$ \\
\hline Scoreboard & A board for displaying students' names and scores for the leading players. \\
\hline Mission/Goal & $\begin{array}{l}\text { Refers to the goal of doing the homework. It requires performing a set of actions and following } \\
\text { the player's journey to accomplish the mission, for instance, finding the treasure. }\end{array}$ \\
\hline Win State & The showing state after achieving the final mission and collecting the rewards. \\
\hline Increasing Difficulty & The feature for raising the difficulty level of questions gradually. \\
\hline Notifications & Kind of announcement to inform students about obtaining rewards or passing exercises. \\
\hline On-boarding/Tutorials & $\begin{array}{l}\text { Set of instructions and illustrations to help students, especially in the first interaction with the } \\
\text { platform, to understand how they achieve their homework by using gamification elements. }\end{array}$ \\
\hline
\end{tabular}

Regarding the instructional design process, we promoted a new scenario for gamifying homework which included the main items of homework exercises and the gamification elements (see Table 4). Consequently, there were 15 exercises divided into both units 3 and 4 taking into consideration the proportionality in skills and question types for each unit.

Table 4. A gamifying homework scenario.

\begin{tabular}{ccccccc}
\hline No & $\begin{array}{c}\text { Exercise } \\
\text { Name }\end{array}$ & $\begin{array}{c}\text { Question } \\
\text { Type }\end{array}$ & $\begin{array}{c}\text { Number of } \\
\text { Questions }\end{array}$ & $\begin{array}{c}\text { Level of } \\
\text { Difficulty }\end{array}$ & $\begin{array}{c}\text { Points } \\
\text { (Total) }\end{array}$ & Level \\
\hline 1 & $\begin{array}{c}\text { Listen } \\
\text { carefully and } \\
\text { answer }\end{array}$ & $\begin{array}{c}\text { Multiple } \\
\text { choice }\end{array}$ & 20 & Easy & 40 & One \\
\hline
\end{tabular}

\subsection{Implementation}

Developing gamification software or a platform is a bit challenging. It requires adequate programming skills and web developers to assure the project success rate. Expanding and adopting successful gamified platforms supports gamified educational activities for carrying out experimental studies to approve the practices [5]. This way, we implemented the online platform "Seppo" for this purpose due to its distinctive features for developing educational games and gamification applications by teachers which can be used efficiently to gamify the learning assignments.

According to the prototype and use cases, the interface was developed as can be seen in Figure 2. The development process was achieved with the iterative procedure in the development cycle. The trial version was released to encourage some researchers to try using the application and recording notes according to their use. This was for detecting any errors in the design. We noticed that some of the participants among the researchers were 
enthusiastic to obtain the highest score so they sought to advance their score by answering the exercises more than once in case they answered wrong. This gave an initial positive indicator about the design. Moreover, we also invited the English teachers to log in on the platform to recognize their feedback on the gamified homework designing and the ease of using the application. They appreciated the idea of a design which boosted completion of the homework. They had some recommendations for adjusting the font face, size, and color, numbering the questions, and fixing some grammatical mistakes.

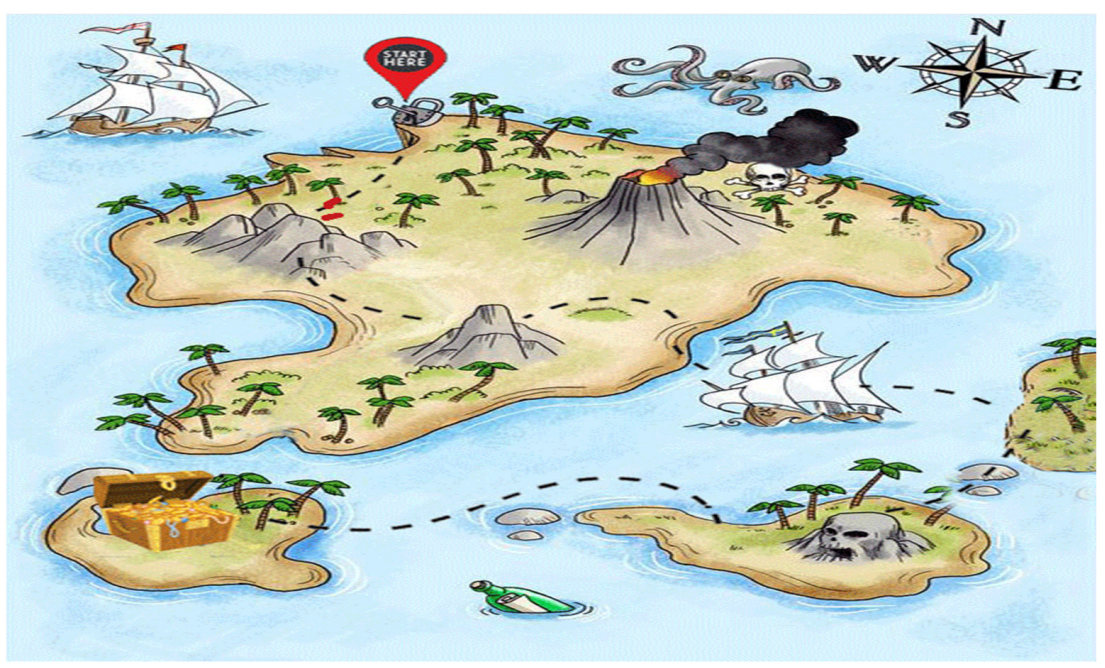

Figure 2. The gamification interface.

Considering these recommendations, the final version was released to start the experiment as shown in Figure 3. Before conducting the experiment, we received approval from an Egyptian school, in accordance with ethical standards. Then, we obtained consent from the students' parents who were informed that the gathered data would be secure and anonymous and that they could leave the research study at any time. The researchers established a session to introduce the application and to provide students with the required information for login through individual accounts and using the main tools on the platform. They could preview the tutorial and instructions for completing the homework on the platform. Students were encouraged to log in on the platform by using their accounts to answer the homework exercises from a personal computer or mobile device. After completing the homework, students were asked to express their feelings and reflections about the gamified homework by writing comments on the platform, so the experiment was accomplished within one month accordingly.

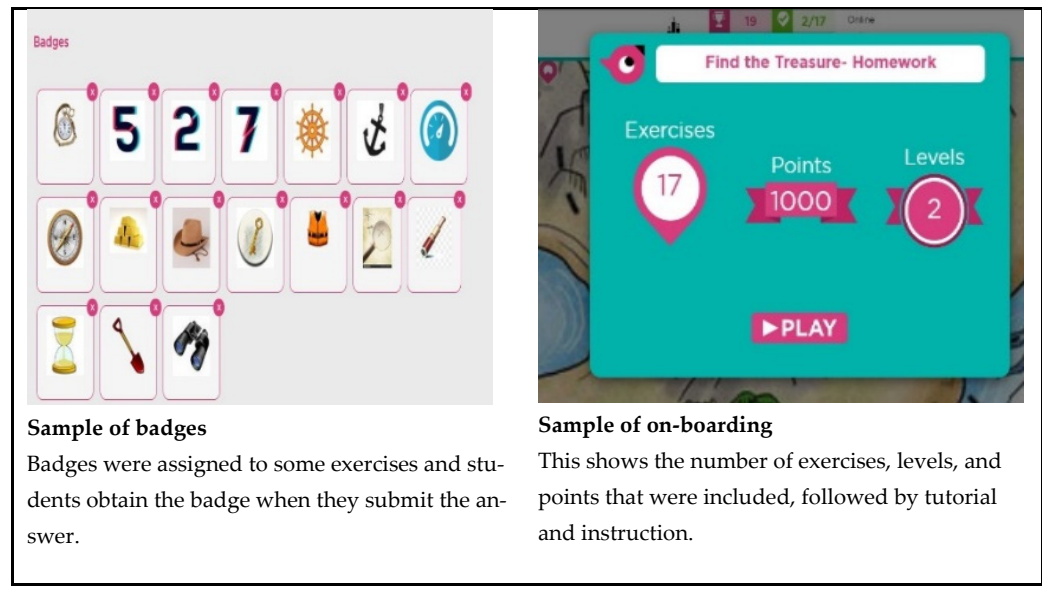

Figure 3. Cont. 


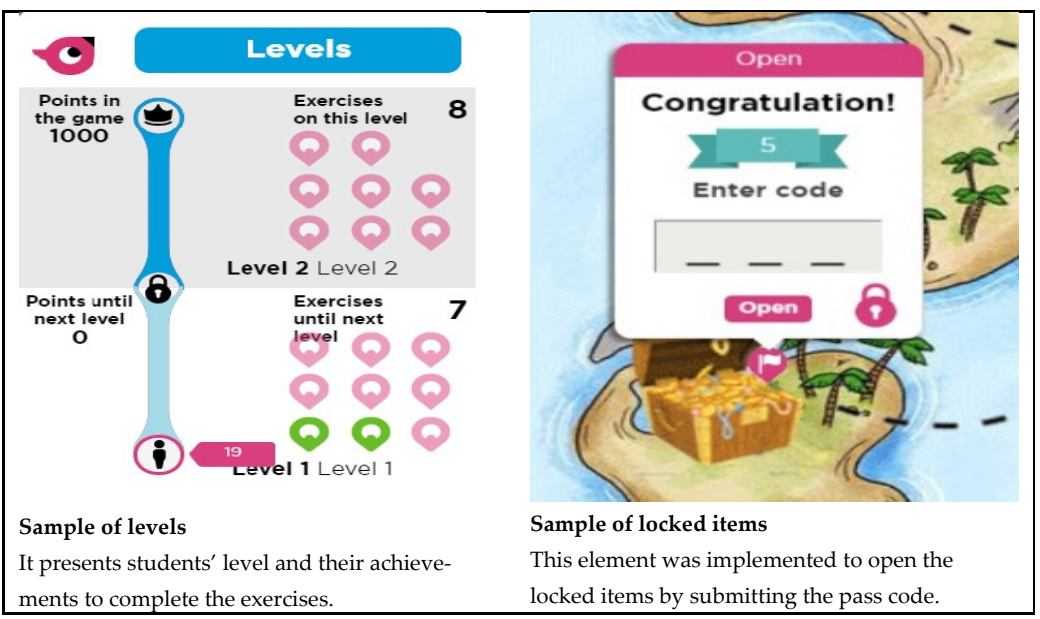

Figure 3. Game elements.

\section{Results}

Data for this research were collected by using learning analytics, surveys, and an interview. In the following sections, the study findings will be described thoroughly.

\subsection{Learning Analytics}

To answer the first research question, "What are the differences between the experimental and control groups in the homework completion regarding the final score?", we captured and reported the students' activities of homework completion after cleaning the data. In all, 25\% of students (10 of 40 students) in the experimental group who achieved the gamified homework were rewarded at least $60 \%$ of the final score (600 points or above of the total 1000 points), while nine students obtained the correct code for unlocking the final item.

On the other hand, in the students' activities of completed homework in the control group without using gamification elements in their assignments, about $68 \%$ of students (30 of 44 students) obtained $60 \%$ of the final score at least (600 points or above of the total 1000 points).

The homework completion according to the total points was analyzed statistically by an independent sample t-test as shown in Table 5, a significant difference was found between the experimental and control groups: $t(82)=5.16, p=0.000$. The mean points of the control group ( $\bar{x}=704.32)$ was higher than the mean of the experimental group $(\bar{x}=463.43)$.

Table 5. Independent sample t-test results according to the final score.

\begin{tabular}{ccccccc}
\hline & $\boldsymbol{n}$ & $\bar{x}$ & $\boldsymbol{S d}$ & $\boldsymbol{d f}$ & $\boldsymbol{t}$ & $\boldsymbol{p}$ \\
\hline Experimental group & 40 & 463.43 & 238.99 & \multirow{2}{*}{82} & \multirow{2}{*}{5.16} & 0.000 \\
Control group & 44 & 704.32 & 187.86 & & & \\
\hline
\end{tabular}

To answer the second research question, "What are the differences between the experimental and control groups in the homework completion rates?" for the experimental group, the average completion rate reached $65.8 \%$. There was a drop in achieving or submitting some exercises which were limited with time for submitting the answer or had advanced difficulty level as challenges. For instance, the lowest number of students (14) with a completion rate $35 \%$ completed and submitted the answer before the ending time for Exercise \#4 in Unit 3 which is constrained by the time-count as shown in Figure 4. 


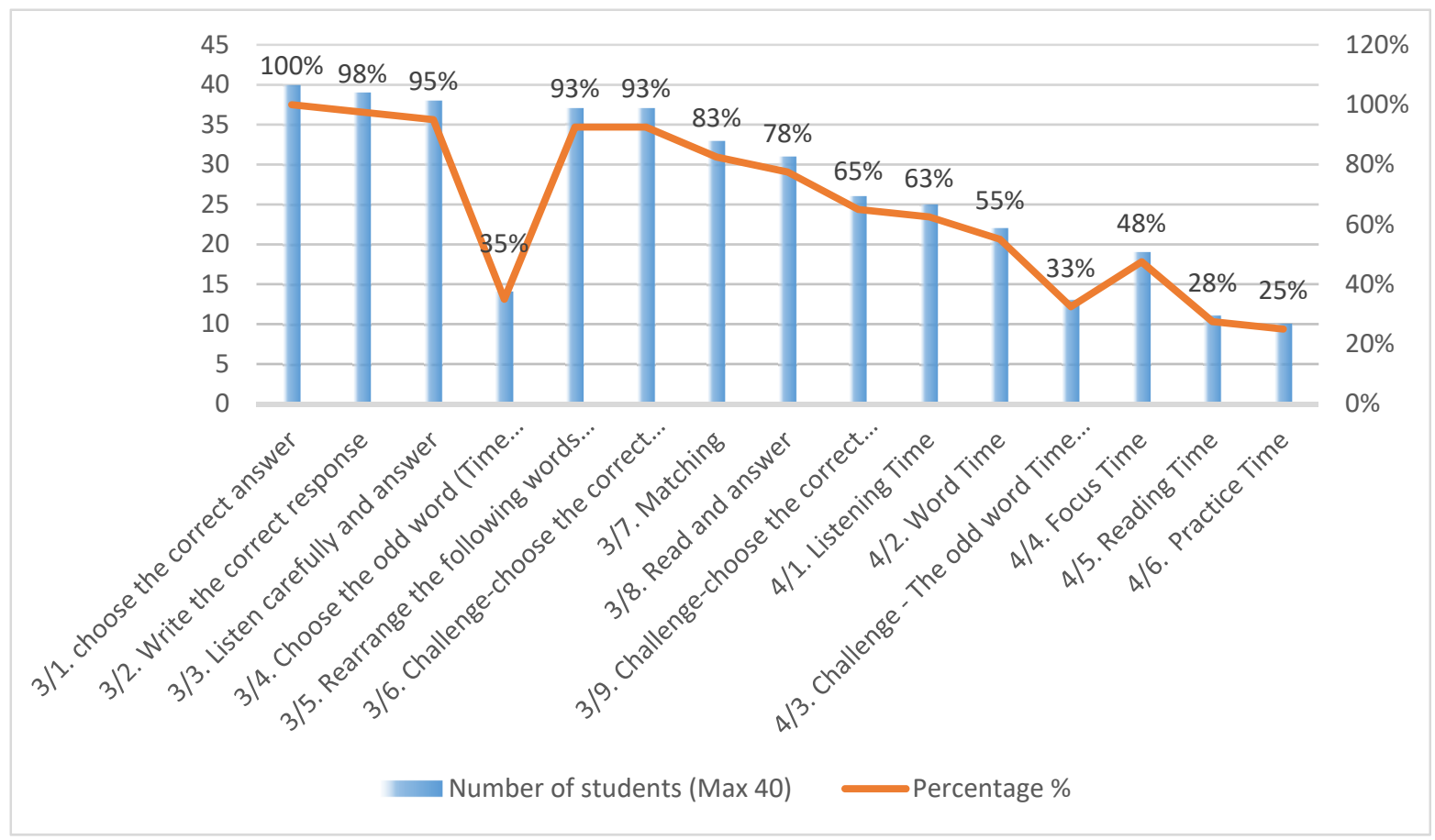

Figure 4. The completion percentage of homework exercises for the experimental group.

In the case of the control group, there was consistency in the homework completion percentage among the exercises as presented in Figure 5 with the average completion rate $(89.5 \%)$.

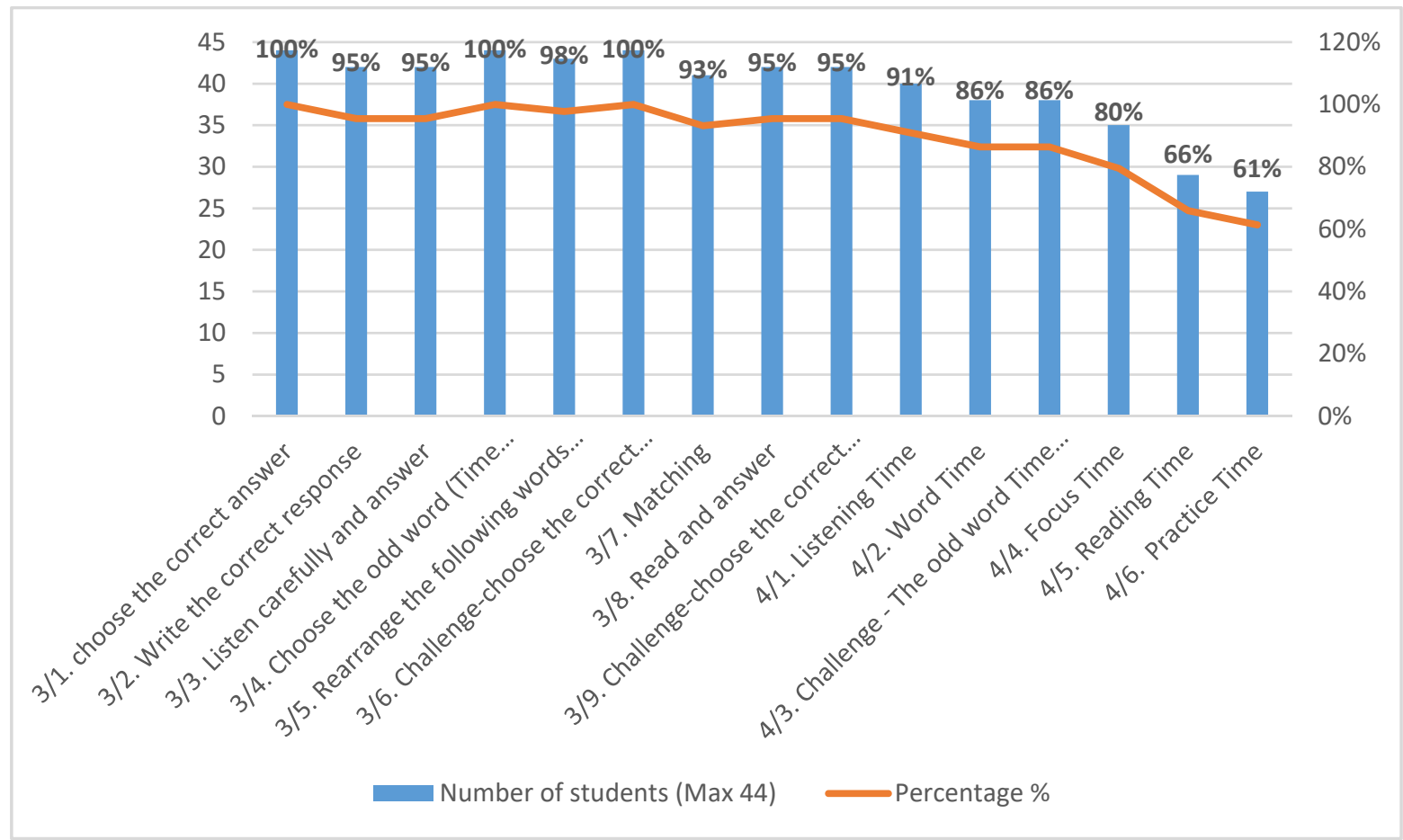

Figure 5. The completion percentage of homework exercises for the control group.

The exercises' completion rates according to the number of students were analyzed statistically by an independent sample t-test as seen in Table 6, a significant difference was found between the experimental and control groups: $t(28)=4.16, p=0.000$. The mean 
exercises' completion score of the control group $(\bar{x}=39.40)$ was higher than the mean of the experimental group $(\bar{x}=26.33)$ which indicates a significant completion increase compared to the experimental group.

Table 6. Independent sample t-test results according to exercises completion rates.

\begin{tabular}{ccccccc}
\hline & $n$ & $\bar{x}$ & $\boldsymbol{s d}$ & $\boldsymbol{d f}$ & $\boldsymbol{t}$ & $\boldsymbol{p}$ \\
\hline Experimental group & 15 & 26.33 & 10.97 & \multirow{2}{*}{28} & \multirow{2}{*}{4.16} & .000 \\
Control group & 15 & 39.40 & 5.29 & & & \\
\hline
\end{tabular}

\subsection{Survey}

The third research question was "What is the perceived feedback about completing homework assignments between the experimental and control groups?" To answer this question, we encouraged students to answer the presented automated questions of the optional survey voluntarily, so we obtained a few responses. In terms of students' feedback from both groups, the survey results showed that some students were excited to use the online platform for learning and doing homework. They spent about 20-30 min daily on homework and had preparation time for reading before starting their homework as shown in Figure 6.
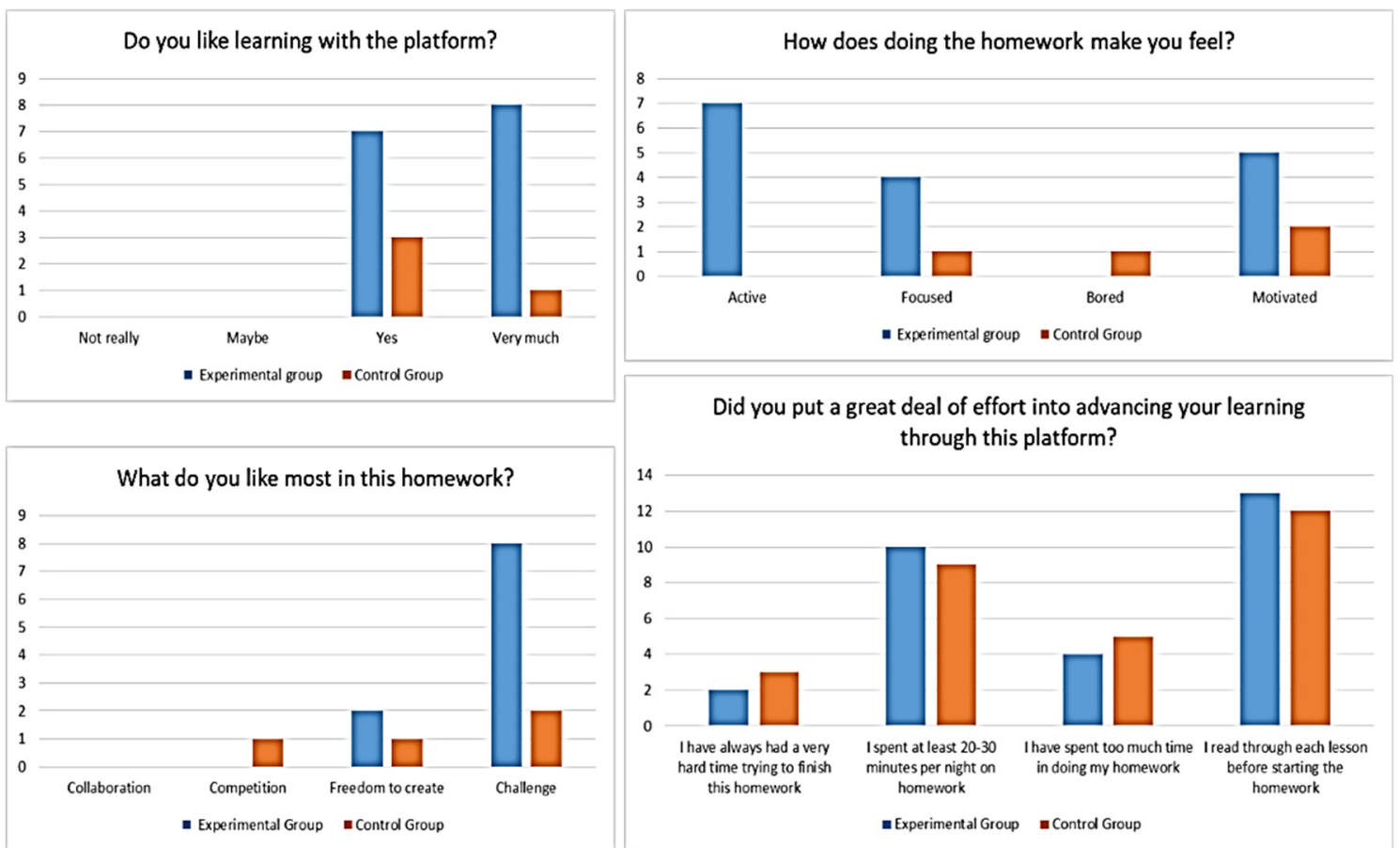

Figure 6. The results of students' feedback about achieving the homework assignments.

The optimistic responses indicated that students praised the application for learning and doing the gamified homework exercises where they were active, motivated, focused, and enjoyed the challenges. Furthermore, few students reported that they had a hard time trying to finish their homework on the platform. Some of the control group students liked learning through the platform. Some students spent too much time on homework accomplishment in which they felt bored and were not quite motivated or focused compared to the experimental group. This finding still denotes the positive perceived feedback about the gamified homework.

To enrich the finding for deep understanding, we sought to connect the qualitative data with the last finding for both the experimental and control groups in a way that we can confirm and validate the results by comparing the comment with the obtained score on 
the platform. In other words, we matched the score of the experimental group students who dominated the leaderboard (ranked number 1 and number 4 ) with their feedback and comments on the platform after completing the homework compared to the feedback of another student in an average ranking. It is crucial to mention that the students' status on the leaderboard in the experimental group is visible and active for all students unlike the students' status of the control group. This function was disabled to fulfil the experimental setting, but we obtained these data through the admin panel. Below are the comments made by students as stated and quoted in Table 7 .

Table 7. Students' comments.

\begin{tabular}{|c|c|}
\hline $\begin{array}{l}\text { Comments of } \\
\text { Experimental Group Students }\end{array}$ & $\begin{array}{l}\text { Comments of } \\
\text { Control Group Students }\end{array}$ \\
\hline $\begin{array}{l}\text { "It's very fun and interactive. Questions were very } \\
\text { easy. The only problem is that it glitches so I lost } \\
\text { points because I couldn't answer a question, or I } \\
\text { couldn't edit my answer, etc. I also clicked on the } \\
\text { wrong answer accidentally a couple of times. But } \\
\text { overall a great app" } \\
\text { Made by the dominant student on the } \\
\text { leaderboard (ranked No.1). Total points }=894\end{array}$ & $\begin{array}{l}\text { "I found it useful to receive new information or } \\
\text { review old information in an easy way. I like the } \\
\text { form of questions, I have enjoyed" } \\
\text { Made by the first student on the rank (ranked } \\
\text { No.1). Total points = } 993\end{array}$ \\
\hline $\begin{array}{l}\text { "It was a good game and intending way to improve } \\
\text { grammar and vocabulary" } \\
\text { Made by the dominant student on the } \\
\text { leaderboard (ranked No.4). Total points }=825\end{array}$ & $\begin{array}{l}\text { "1-The homework contains a variety of questions. } \\
\text { 2-Develop thinking and realizing } \\
\text { 3-Development the hearing skills by listening audio" } \\
\text { Made by the fourth student on the rank } \\
\text { (ranked No.4). Total points }=923\end{array}$ \\
\hline \multicolumn{2}{|c|}{$\begin{array}{l}\text { Moreover, there is more positive feedback from a student who completed all the exercises with an } \\
\text { average score comparing to the dominant students on the leaderboard. }\end{array}$} \\
\hline $\begin{array}{l}\text { "I'm happy to play that game } \\
\text { I benefit from this program } \\
\text { It is very important" } \\
\text { Made by a student who completed all the } \\
\text { exercises }\end{array}$ & $\begin{array}{l}\text { "I like the different categories of question and the } \\
\text { question easy in different stage. It's provided me a } \\
\text { lot of experiences thank you for great effort" } \\
\text { Made by a student who completed all the } \\
\text { exercises }\end{array}$ \\
\hline
\end{tabular}

\subsection{Interview}

A semi-structured interview was carried out face-to-face to determine students' perceptions of the gameful experience in homework assignments. We received informed consent from the study participants of the experimental group (both students and their parents). They also knew that they were free to withdraw from the interview at any time, and that the data were analyzed anonymously. It is worth indicating that the interviewers used "game" instead of "gamification" synonymously during the interview, as the game concept is familiar for students.

We opted for grounded theory methods [47]. There were 14 valid responses to the interview from the experimental group. The interview data were transcribed at the end of the interviews. A template analysis guide was applied to analyze the data for generating possible themes [48]. Students' opinions in terms of gamification aspects were classified under five different themes titled "good design, the thrill of solving the mystery, selfcontrol, points, and challenges". In response to the first question, most of those interviewed indicated that good design and the thrill of solving the mystery of reaching the treasure were the items that most increased engagement and motivation. Moreover, the self-control of the gamified homework helped them to learn the necessary skills according to their own pace as shown in Figure 7. 


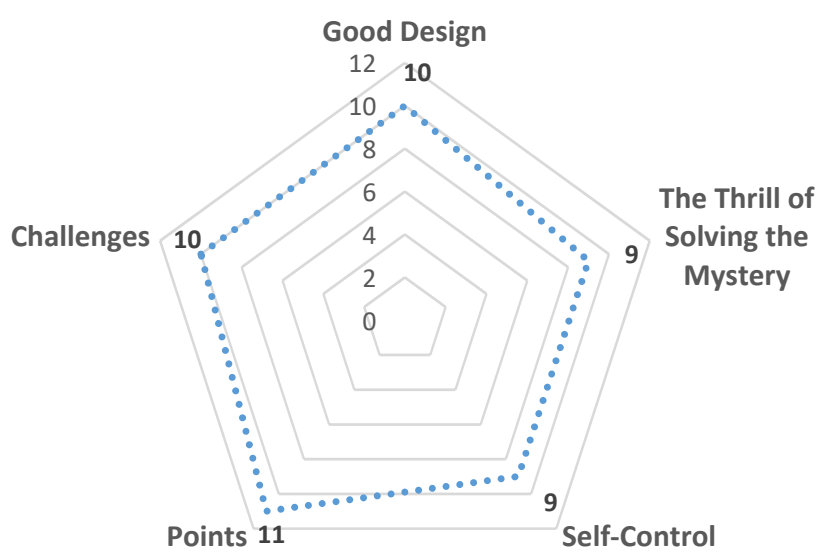

Figure 7. The most helpful aspects of the gamified homework.

Nearly $70 \%$ of those who were interviewed indicated that the exercises they completed during the game were easy and accessible to their level, and they expected more than $65 \%$ of the scores as presented in Figure 8.

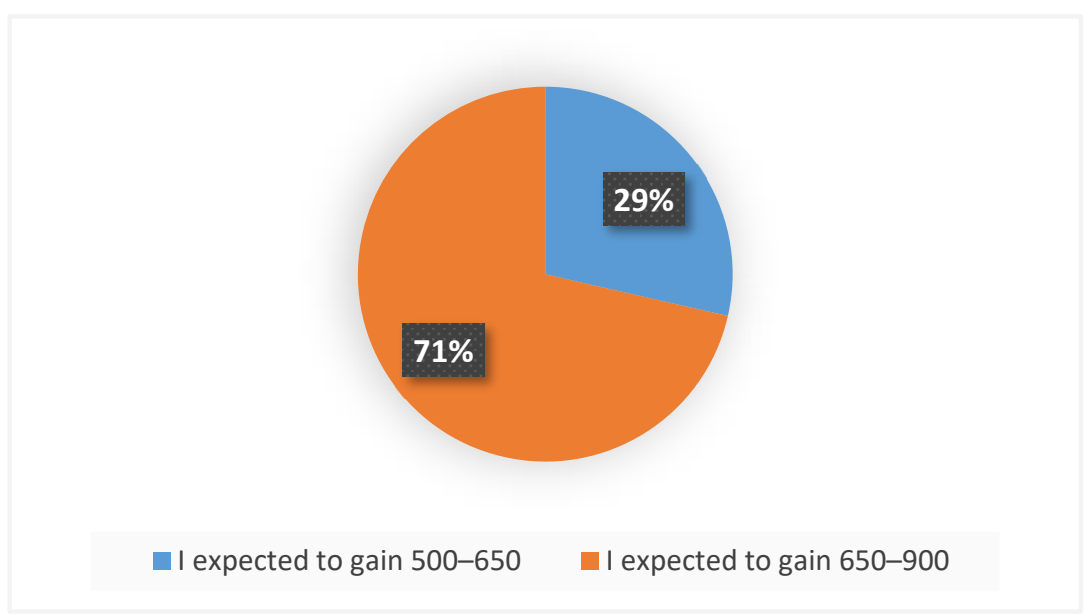

Figure 8. The expectation of collecting points.

The majority of those who responded to the question "what parts of the game were obstacles to your learning?" felt that the technical problems and loading time were the most problematic during the homework accomplishment. Moreover, seven students referred and drew attention to the need for operating further instructions to find the treasure.

Respondents were asked to suggest some specific recommendations for improving this educational gamification app. They suggested (1) that they prefer to work in cooperative groups rather than through individual learning, (2) creating a set of unique incentives that are appropriate for a number of unique students, (3) reducing page loading times, (4) giving real-time feedback during the homework and activating chat with the teacher to discuss some technical and homework issues, and (5) providing a dashboard and reports on the progress level, including students' strengths and weaknesses.

\section{Discussion}

The final score of the homework exercises indicated that the control group completion rates were higher than the experimental group. The possible interpretation could return 
to using some gamification mechanics like time-constraints that obstructed collecting points easily, or the gameful design requires more concentration when students need to collect the badges to find the correct passcode whereas achieving the homework in the control group does not entail finding the badges or answering in limited time. This finding is partly consistent with the finding of Magalhães et al. [18] that showed that online homework helped students to complete the learning assignments. However, the positive feedback, comments, and the perceived gamified homework experience of the experimental group denoted that the gameful experience was distinguished by using points, badges, and rewards mechanisms in addition to the gameful design. Gamification mechanics are the motivational affordances to enforce the motivation for achieving the learning assignments but do not guarantee student performance [4,13]. Time constraints mechanics were effective to motivate some students who prefer the challenge spirits. However, it obstructed the students who failed to answer the questions under time pressure, so it caused the decline of completion rates in the exercises that used this mechanic. This finding is in line with Huang et al. [49] where the analysis showed that the activities which were related to the time were not significant. Thus, we have to consider the unpleasant effect of time pressure [50].

In terms of analyzing homework completion rates, low completion percentages in some exercises were observed because of the time constraints mechanic, or challenges that required higher levels of thinking. However, we cannot rely only on the completion rates to evaluate the experience, so we implemented a survey and interview to verify the finding. Points were used as an indicator to investigate the efficacy in the gamebased system to solve homework problems [51]. Obtaining the highest was is not only the target of applying gamification. Badges also did not impact the final score [35], but enhanced students' motivation [52]. Gamifying homework aims to increase motivation and engagement for enjoying homework achievement by carefully implementing the game elements.

Regarding feedback from students who participated in the survey, the experimental group appreciated the gamified homework for its role in the learning process. This is in line with the findings which revealed that gamified e-quiz exercises contributed to engaging students in learning [53]. Students expressed positive perceptions and were enthusiastic about doing homework assignments [34,54], unlike students' feedback from the control group; however, few students were motivated to complete their homework on the platform. Gamifying homework changed the perception of the learning tasks; hence, the positive feedback from the experimental group outweighed the control group's feedback. Furthermore, challenge-based gamification is seen as helpful to support students' learning [55].

Comparing the written comments on the platform after completing the assignments between some students of the experimental and control groups and matching them with the results of the survey proved the usefulness of homework on the platform in terms of supporting the English language learning, including grammar, vocabulary, and listening. It also asserted the value of converting homework in an enticing way from the conventional one.

The interview findings highlighted the self-control feature as an important aspect in the gamified homework. It can foster intrinsic motivation that connects the main psychological needs: "competence, autonomy, and relatedness" [56]. Students' expectation rates of obtaining a high score indicated their interaction with the design. Although students made efforts to advance their learning, a few students had a hard time trying to finish their homework. This can be interpreted as being due to the possible technical problems and loading time issues they faced. Moreover, students who were struggling in school spent a long time to achieve their homework [17]. The interview finding confirmed the survey results where students appreciated the good design, the thrill of solving the mystery, points, and challenges as the most helpful features in the gamified homework. This result is particularly relevant to the theory of gameful experience [23]. The gameful design in the 
gamified homework system reflected on student's perceptions and promoted the gameful experience. Students suggested a set of recommendations from their perspectives of achieving assignments which included achieving the learning tasks in cooperative groups and activating the real-time feedback of the instructor. It confirmed the momentousness of supporting students with different kinds of feedback [54]; instant feedback could enhance the intrinsic motivation for learning English [57]. As a practical implication, the effective design of the gamified homework should concern the extrinsic and intrinsic affordances that enhance the gameful experience. These inclusions require particular investigation in the future with applying the principles of human-computer interaction $(\mathrm{HCI})$ and user experience (UX). This way, the research suggests coming up with innovative design strategies for enhancing the perceived gameful experience in gamifying the learning assignments.

\section{Conclusions}

\subsection{Summary}

The present study aims to determine and evaluate students' perception of gamifying homework. Approaching gamification with learning assignments is an interactive approach to inspire students to learn through the use of web-based-game design and gaming elements in learning environments. Our objective is to maximize enjoyment and engagement by capturing learners' interest and inspiring them to continue learning. Thus, we developed a gamification application to help students doing their homework. The most noticeable finding to extract from this study is that the students perceived the homework assignments positively by using a gamified homework application. Moreover, the study highlighted that feedback should be issued as promptly as possible and should be sensitive to the student's individual needs. It would be worth coming up with personalization of gamification homework in accordance with some endeavors in this research track. Applying the gamification strategies in the classroom along with the gamified system in the way to integrate the gamified activities would be recommended as a future direction.

\subsection{Limitations}

The first limitation concerns the small number of participants $(n=40)$ of the experimental group from one primary school. Rectifying this requires extending the investigation to different grades and increasing the study sample. This may cause a lack of investigation into other identification or insights to recognize some differences for students in other grades or the demographic differences, including gender.

The second limitation goes to impl ementing the gamified homework in the English course so the generalization of this research's findings cannot be confirmed to evaluate its effectiveness in other courses or subjects or whether gamification might also work differently in case of another kind of learning activities.

The third limitation is that the period of experimenting was short for recognizing the effect of gamification. It would be worth investigating the intervention for a long time by conducting a longitudinal study.

The fourth limitation concerns the measurement tools and instruments. This research sought to identify the influence of the gamified homework on students' ability to complete learning tasks, as well as investigating the perceived gameful experience by using learning analytics, surveys, and interview measurements. It is indispensable to conduct follow-up research for applying or developing other instruments to investigate the gameful experience as well as the learning analytics mechanism.

\subsection{Future Work}

While this research evaluates students' reflections and perceptions of the gameful experience of homework assignments, there are certainly several recommended variables and issues for future works. Examining the effects of gamifying homework through longitudinal studies is highly recommended to avoid "the novelty effects" [40], with a further analysis of the perceived gamification experiences alongside a convenient sample 
to strengthen the reliability of the experimental design. Furthermore, this research suggests examining learning styles and personalized gamification elements in the homework context, in addition to cognitive load and behavior change [58]. This research suggests developing instruments to investigate the gameful experience as well as the learning analytics mechanism, expanding the gamification application accessibility to mobile apps that promote learning outside the classroom, exploring the leading factors and the possible threats that affect the gamified homework [59], and lastly, the research suggests examining gamification effects in the classroom setting by utilizing tangible rewards.

Author Contributions: Conceptualization, A.H.S.M., M.C., Y.W., and A.M.F.Y.; methodology, A.H.S.M., M.C., and A.M.F.Y.; software, A.H.S.M.; validation, A.H.S.M. and A.M.F.Y.; formal analysis, A.H.S.M. and A.M.F.Y.; investigation, A.M.F.Y.; resources, A.M.F.Y.; data curation, A.H.S.M. and A.M.F.Y.; writing—original draft preparation, A.H.S.M.; writing—review and editing, A.H.S.M., M.C., Y.W., and A.M.F.Y.; visualization, A.H.S.M. and A.M.F.Y.; supervision, Y.W. All authors have read and agreed to the published version of the manuscript.

Funding: This research received no external funding.

Institutional Review Board Statement: Not applicable.

Informed Consent Statement: Informed consent was obtained from all subjects involved in the study.

Data Availability Statement: The data presented in this study are available on reasonable request from the corresponding author.

Acknowledgments: We would like to express our special thanks to Northeast Normal University for supporting this research. We would also like to thank the Seppo team for providing us an open license with unlimited usage during our investigation.

Conflicts of Interest: The authors declare no conflict of interest.

The research experiment can be accessed when logging in as a player at: play.seppo.io; with the pin code: 19AFA3, or by scanning the QR code, as shown in the following figure.

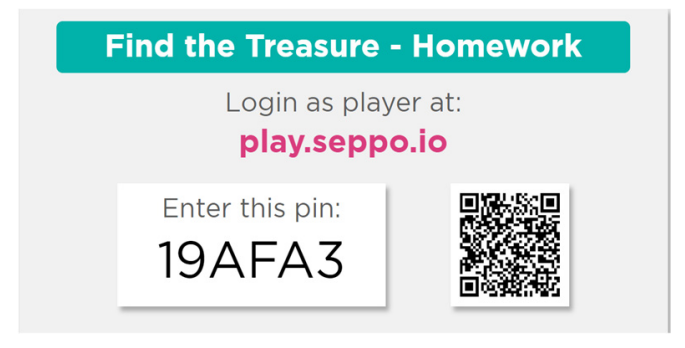

\section{References}

1. Zainuddin, Z.; Chu, S.K.W.; Shujahat, M.; Perera, C.J. The impact of gamification on learning and instruction: A systematic review of empirical evidence. Educ. Res. Rev. 2020, 30. [CrossRef]

2. Eppmann, R.; Bekk, M.; Klein, K. Gameful Experience in Gamification: Construction and Validation of a Gameful Experience Scale [GAMEX]. J. Interact. Mark. 2018, 43, 98-115. [CrossRef]

3. Chee, C.M.; Wong, D.H. Ten Affluent Gaming Experience Could Fail Gamification in Education: A Review. IETE Tech. Rev. (Institution Electron. Telecommun. Eng. India) 2017, 34, 593-597. [CrossRef]

4. Caporarello, L.; Magni, M.; Pennarola, F. One Game Does not Fit All. Gamification and Learning: Overview and Future Directions. In Organizing for Digital Innovation. Lecture Notes in Information Systems and Organisation; Lazazzara, A., Nacamulli, R.C.D., Rossignoli, C., Za, S., Eds.; Springer: Cham, Switzerland, 2019; Volume 27, pp. 179-188.

5. Dichev, C.; Dicheva, D. Gamifying education: What is known, what is believed and what remains uncertain: A critical review. Int. J. Educ. Technol. High. Educ. 2017, 14. [CrossRef]

6. Dehghanzadeh, H.; Fardanesh, H.; Hatami, J.; Talaee, E.; Noroozi, O. Using gamification to support learning English as a second language: A systematic review. Comput. Assist. Lang. Learn. 2019. [CrossRef]

7. Kayimbaşioğlu, D.; Oktekin, B.; Haci, H. Integration of Gamification Technology in Education. Procedia Comput. Sci. 2016, 102, 668-676. [CrossRef]

8. Zarzycka-Piskorz, E. Kahoot It or Not? Can Games Be Motivating in Learning Grammar? Teach. Engl. Technol. 2016, 16, 17-36. 
9. Galloway, M.; Conner, J.; Pope, D. Nonacademic effects of homework in privileged, high-performing high schools. J. Exp. Educ. 2013, 81, 490-510. [CrossRef]

10. Dettmers, S.; Trautwein, U.; Lüdtke, O.; Goetz, T.; Frenzel, A.C.; Pekrun, R. Students' emotions during homework in mathematics: Testing a theoretical model of antecedents and achievement outcomes. Contemp. Educ. Psychol. 2011, 36, 25-35. [CrossRef]

11. Nacke, L.E.; Deterding, S. The maturing of gamification research. Comput. Human Behav. 2017, 71, 450-454. [CrossRef]

12. Butler, B.L.; Bodnar, C.A. Establishing the Impact that Gamified Homework Portals Can Have on Students' Academic Motivation. In Proceedings of the 2017 ASEE Annual Conference \& Exposition, Columbus, OH, USA, 25-28 June 2017.

13. Goehle, G.; Wagaman, J. The Impact of Gamification in Web Based Homework. PRIMUS Probl. Resour. Issues Math. Undergrad. Stud. 2015, 26, 557-569. [CrossRef]

14. Kulhanek, A.; Butler, B.; Bodnar, C.A. Motivating first-year engineering students through gamified homework. Educ. Action Res. 2019, 1-26. [CrossRef]

15. Roschelle, J.; Feng, M.; Murphy, R.F.; Mason, C.A. Online Mathematics Homework Increases Student Achievement. AERA Open 2016, 2, 1-12. [CrossRef]

16. Sailer, M.; Homner, L. The Gamification of Learning: A Meta-analysis. Educ. Psychol. Rev. 2020, 32, 77-112. [CrossRef]

17. Cooper, H.; Robinson, J.C.; Patall, E.A. Does homework improve academic achievement? A synthesis of research, 1987-2003. Rev. Educ. Res. 2006, 76, 1-62. [CrossRef]

18. Magalhães, P.; Ferreira, D.; Cunha, J.; Rosário, P. Online vs traditional homework: A systematic review on the benefits to students' performance. Comput. Educ. 2020, 152. [CrossRef]

19. Pelling, N. The (Short) Prehistory of “Gamification". Available online: https://nanodome.wordpress.com/2011/08/09/theshort-prehistory-of-gamification/ (accessed on 3 May 2020).

20. Deterding, S.; Dixon, D.; Khaled, R.; Nacke, L. From game design elements to gamefulness: Defining "gamification". In Proceedings of the 15th International Academic MindTrek Conference: Envisioning Future Media Environments, Tampere, Finland, 28-30 September 2011; pp. 9-15. [CrossRef]

21. O’Donnell, N.; Kappen, D.L.; Fitz-Walter, Z.; Deterding, S.; Nacke, L.E.; Johnson, D. How Multidisciplinary is Gamification Research? Results from a Scoping Review. In Proceedings of the CHI PLAY '17 Extended Abstracts Publication of the Annual Symposium on Computer-Human Interaction in Play, Amsterdam, The Netherlands, 15-18 October 2017; pp. 445-452. [CrossRef]

22. Peixoto, M.; Silva, C. A gamification requirements catalog for educational software: Results from a systematic literature review and a survey with experts. In Proceedings of the ACM Symposium on Applied Computing; Association for Computing Machinery, New York, NY, USA, 2017; Volume F1280, pp. 1108-1113.

23. Landers, R.N.; Tondello, G.F.; Kappen, D.L.; Collmus, A.B.; Mekler, E.D.; Nacke, L.E. Defining gameful experience as a psychological state caused by gameplay: Replacing the term 'Gamefulness' with three distinct constructs. Int. J. Hum. Comput. Stud. 2019, 127, 81-94. [CrossRef]

24. Majuri, J.; Koivisto, J.; Hamari, J. Gamification of education and learning: A review of empirical literature. In Proceedings of the 2nd International GamiFIN Conference, Pori, Finland, 21-23 May 2018; pp. 11-19.

25. Bozkurt, A.; Durak, G. A systematic review of gamification research: In pursuit of homo ludens. Int. J. Game Based Learn. 2018, 8, 15-33. [CrossRef]

26. Cooper, H. Homework; White Plains; Longman: London, UK, 1989.

27. Bempechat, J. The motivational benefits of homework: A social-cognitive perspective. Theory Pract. 2004, 43, 189-196. [CrossRef]

28. Fan, H.; Xu, J.; Cai, Z.; He, J.; Fan, X. Homework and students' achievement in math and science: A 30-year meta-analysis, 1986-2015. Educ. Res. Rev. 2017, 20, 35-54. [CrossRef]

29. Dodson, R.J. The impact of online homework on class productivity. Sci. Educ. Int. 2014, 25, 354-371.

30. Fratto, V.; Sava, M.G.; Krivacek, G.J. The impact of an online homework management system on student performance and course satisfaction in introductory financial accounting. Int. J. Inf. Commun. Technol. Educ. 2016, 12, 76-87. [CrossRef]

31. Bembenutty, H.; White, M.C. Academic performance and satisfaction with homework completion among college students. Learn. Individ. Differ. 2013, 24, 83-88. [CrossRef]

32. Simões, J.; Mateus, S.; Redondo, R.; Vilas, A. An Experiment to Assess Students' Engagement in a Gamified Social Learning Environment. eLearning Pap. 2015, 43, 38-42. [CrossRef]

33. Metwally, A.H.S.; Yousef, A.M.F.; Yining, W. Investigating the effects of gamifying homework on students' perceived satisfaction, behavioral intention and intrinsic motivation. In Proceedings of the 3rd International GamiFIN Conference, CEUR Workshop, Levi, Finland, 8-10 April 2019; Volume 2359, pp. 47-57.

34. Goehle, G. Gamification and Web-based Homework. PRIMUS Probl. Resour. Issues Math. Undergrad. Stud. 2013, 23, 234-246. [CrossRef]

35. Hakulinen, L.; Auvinen, T.; Korhonen, A. The Effect of Achievement Badges on Students' Behavior: An Empirical Study in a University-Level Computer Science Course. Int. J. Emerg. Technol. Learn. 2015, 10, 18-29. [CrossRef]

36. Uanhoro, J.; Young, S.S.-C.; Lin, Y.-H. Empirical study on the effect of digital badges in a general physics homework system. In Proceedings of the ICCE 2016 - 24th International Conference on Computers in Education: Think Global Act Local, Bombay, India, 28 November-2 December 2016; pp. 232-241.

37. Hevner, A.R.; March, S.T.; Park, J.; Ram, S. Design science in information systems research. MIS Q. 2004, 28, 75-105. [CrossRef]

38. Gribbons, B.; Herman, J. True and Quasi-Experimental Designs. Pract. Assess. Res. Eval. 1996, 5. [CrossRef] 
39. Merriam, S.B. Qualitative Research: A Guide to Design and Implementation; Jossey-Bass: San Francisco, CA, USA, 2009.

40. Koivisto, J.; Hamari, J. The rise of motivational information systems: A review of gamification. Int. J. Inf. Manage. 2019, 45, 191-210. [CrossRef]

41. Fricker, R.D.J. Sampling methods for web and e-mail surveys. In The SAGE Handbook of Online Research Methods; Lee, R.M., Blank, G., Eds.; Sage Publications Ltd: London, UK, 2008; pp. 195-216.

42. Morschheuser, B.; Hamari, J.; Werder, K.; Abe, J. How to Gamify? A Method For Designing Gamification. In Proceedings of the 50th Hawaii International Conference on System Sciences, Hilton Waikoloa Village, HI, USA, 4-7 January 2017; pp. 1298-1307.

43. Usability.gov Use Cases. Available online: https://www.usability.gov/how-to-and-tools/methods/use-cases.html (accessed on 25 February 2021).

44. Chen, C.-T.; Chang, M.; Wu, K.-H.; Yu, P.-S. Web-based Conversation Quest for Enhancing English Speaking Skills. In Proceedings of the 26th International Conference on Computers in Education, Manila, Philippines, 26-30 November 2018; pp. 652-660.

45. Werbach, K.; Hunter, D. For the Win: How Game Thinking Can Revolutionize Your Business; Wharton Digital Press: Philadelphia, PA, USA, 2012.

46. Landers, R.N.; Armstrong, M.B.; Collmus, A.B. How to use game elements to enhance learning: Applications of the theory of gamified learning. In Serious Games and Edutainment Applications: Volume II; Springer: London, UK, 2017.

47. Charmaz, K.; Belgrave, L.L. Grounded Theory. In The Blackwell Encyclopedia of Sociology; American Cancer Society: Atlanta, GA, USA, 2015.

48. Brooks, J.; McCluskey, S.; Turley, E.; King, N. The Utility of Template Analysis in Qualitative Psychology Research. Qual. Res. Psychol. 2015, 12, 202-222. [CrossRef]

49. Huang, R.; Ritzhaupt, A.D.; Sommer, M.; Zhu, J.; Stephen, A.; Valle, N.; Hampton, J.; Li, J. The impact of gamification in educational settings on student learning outcomes: A meta-analysis. Educ. Technol. Res. Dev. 2020, 68, 1875-1901. [CrossRef]

50. Garcia-Iruela, M.; Hijón-Neira, R. What Perception Do Students Have About the Gamification Elements? IEEE Access 2020, 8 , 134386-134392. [CrossRef]

51. Wang, C.; Hsu, Y.; Yeh, P.; Road, R.; Lin, C.; Lai, I. Edventure: Gamification for Collaborative Problem Design and Solving. In Proceedings of the 15th International Conference on Information Technology Based Higher Education and Training (ITHET), Istanbul, Turkey, 8-10 September 2016; pp. 1-5.

52. Groening, C.; Binnewies, C. "Achievement unlocked!"- The impact of digital achievements as a gamification element on motivation and performance. Comput. Human Behav. 2019, 97, 151-166. [CrossRef]

53. Zainuddin, Z.; Shujahat, M.; Haruna, H.; Chu, S.K.W. The role of gamified e-quizzes on student learning and engagement: An interactive gamification solution for a formative assessment system. Comput. Educ. 2020, 145, 103729. [CrossRef]

54. Cheong, C.; Flilippou, J.; Cheong, F. Towards the Gamification of Learning: Investigating Student Perceptions of Game Elements. J. Inf. Syst. Educ. 2014, 25, 233-245.

55. Legaki, N.-Z.; Xi, N.; Hamari, J.; Karpouzis, K.; Assimakopoulos, V. The effect of challenge-based gamification on learning: An experiment in the context of statistics education. Int. J. Hum. Comput. Stud. 2020, 144, 102496. [CrossRef]

56. Ryan, R.M.; Deci, E.L. Intrinsic and Extrinsic Motivations: Classic Definitions and New Directions. Contemp. Educ. Psychol. 2000, 25, 54-67. [CrossRef]

57. Sun, J.C.; Hsieh, P. Application of a Gamified Interactive Response System to Enhance the Intrinsic and Extrinsic Motivation, Student Engagement, and Attention of English Learners. Educ. Technol. Soc. 2018, 21, 104-116.

58. Osatuyi, B.; Osatuyi, T.; De La Rosa, R. Systematic review of gamification research in is education: A multi-method approach. Commun. Assoc. Inf. Syst. 2018, 42, 95-124. [CrossRef]

59. Toda, A.M.; Valle, P.H.D.; Isotani, S. The Dark Side of Gamification: An Overview of Negative Effects of Gamification in Education. In Higher Education for All. From Challenges to Novel Technology-Enhanced Solutions. HEFA 2017. Communications in Computer and Information Science; Cristea, A., Bittencourt, I., Lima, F., Eds.; Springer: Cham, Switzerland, 2018; Volume 832, pp. 143-156. 